\title{
Determinantes da Criminalidade: Arcabouços Teóricos e Resultados Empíricos*
}

\author{
Daniel Cerqueira \\ Waldir Lobão
}

\section{INTRODUÇÃO}

Entender o que leva as pessoas a cometer crimes é uma tarefa árdua. Afinal, não há consenso sobre uma verdade universal (ainda que seja uma meia verdade temporária ${ }^{1}$ ), mesmo que esta se refira a uma determinada cultura, em um dado momento histórico. Como explicar que em uma comunidade onde haja dois irmãos gêmeos, um deles enverede pela via do narcotráfico, ao passo que o outro prefira seguir o caminho da legalidade?

\footnotetext{
*Gostaríamos de deixar registrado nosso agradecimento ao professor Luiz Eduardo Soares pela generosidade em compartilhar tantos ensinamentos e pelos momentos felizes e intensos vividos na Coordenadoria de Segurança Pública do Rio de Janeiro. Agradecemos pela fraternal cooperação, aos amigos: Jacqueline Muniz, Julita Lemgruber, Silvia Ramos, Jairo Nicolau, Bárbara Musumeci, Leonarda Musumeci, Ignacio Cano, Túlio Kahn, Yolanda Catão, Roberto Kant de Lima e Claudio Beato. Nosso reconhecimento aos colegas do Instituto de Pesquisa Econômica Aplicada - IPEA pelas enriquecedoras discussões, em especial, a Sergei Soares, pelos sempre pertinentes comentários, e a Roberto Martins, Ricardo Paes de Barros e Lauro Ramos, que tanto apoio deram aos primeiros passos dessa longa jornada de estudos em crime e segurança pública no Brasil. Por fim, gostaríamos de expressar nossa gratidão aos dois pareceristas anônimos de Dados, que nos brindaram com valiosas e perspicazes sugestões que permitiram o aprimoramento deste trabalho.
}

DADOS - Revista de Ciências Sociais, Rio de Janeiro, Vol. 47, no2, 2004, pp. 233 a 269. 
Os criminólogos que, principalmente a partir do início do século XX, estudaram o assunto identificaram uma série de fatores criminogênicos que, combinados em proporções e situações específicas, poderiam explicar a causação do crime. Desse modo, o que há na literatura são inúmeros modelos que focalizam alguns fatores em particular. Portanto, melhor do que perceber cada um dos modelos como uma panacéia que explique situações tão díspares, ou mesmo como modelos que dêem conta da generalidade do mundo criminal, menos ingênuo seria interpretá-los como matizes que podem ajudar a compor um quadro.

Do ponto de vista da intervenção pública para a manutenção da paz social, não importa conhecer a verdade. Importa, antes de mais nada, reconhecer se em uma determinada região há alguma regularidade estatística entre aqueles fatores criminogênicos, concretos (presença de armas, drogas etc.), ou imaginários (supervisão familiar, reconhecimento etc.), e, além disso, saber se o Estado possui instrumentos para intervir nessa regularidade, direta ou indiretamente, com a participação da própria sociedade. As teorias de causação do crime, ao lançarem luz sobre determinadas variáveis e sua epidemiologia, permitem que o planejador do Estado escolha dentre inúmeras variáveis aquelas que supostamente devem ser as mais importantes. Os modelos empíricos, ao detalharem a metodologia de aferição, possibilitam a centralização das atenções e dos escassos recursos públicos em algumas poucas variáveis, que podem não explicar uma verdade universal, mas interferem decisivamente (com maior probabilidade) na dinâmica criminal daquela região onde se quer intervir. Desse modo, o planejador público que acreditar piamente em um único modelo de causação criminal (seja qual for) para tomar suas decisões e orientar suas ações e recursos estará fadado a utilizar um "leito de Procusto", algumas vezes com êxito, outras não, a depender do "cliente" ou da situação em particular. Daí a necessidade da multidisciplinaridade: um meio de aumentar o conjunto de instrumentos de análise e de intervenção pública para um objeto extremamente complexo.

Elaborar um estudo exaustivo sobre os inúmeros modelos e trabalhos no campo da etiologia criminal seria uma proposta por demais pretensiosa, para não dizer impossível, no escasso espaço de um artigo. Portanto, reconhecemos haver no presente trabalho certas omissões, principalmente no campo das pesquisas com orientações antropológicas, que cobrem um riquíssimo espectro de possibilidades e objetos 
de análise. Tais lacunas derivam ainda da perspectiva fortemente empírica, por nós adotada, de tentar compreender alguns importantes elementos causadores da criminalidade e a possibilidade de sua aferição empírica em determinadas realidades, ressaltando, sempre que possível, as limitações e o alcance dos resultados, mormente como ferramentas para a elaboração de políticas de intervenção reguladora do Estado.

\section{EVOLUÇÃO DOS ESTUDOS SOBRE AS CAUSAS DA CRIMINALIDADE}

Os estudos sobre as causas da criminalidade têm se desenvolvido em duas direções: naquela das motivações individuais e na dos processos que levariam as pessoas a se tornarem criminosas. Por outro lado, tem-se estudado as relações entre as taxas de crime em face das variações nas culturas e nas organizações sociais. Tais arcabouços teóricos vêm sendo desenvolvidos, principalmente, a partir de meados do século passado.

Em períodos anteriores, as primeiras reflexões sobre o tema, elaboradas normalmente por pessoas fora do círculo acadêmico, procuravam encontrar uma causa geral para o comportamento criminoso, de sorte que, virtualmente, ao extirpá-la se conseguiria erradicar a criminalidade. Contudo, tais perspectivas se traduziam menos em teorias explicativas sobre a criminalidade e mais em panacéias que alimentavam o discurso de teólogos, reformadores e médicos da época. Nesse limiar do desenvolvimento teórico da criminologia, uma das mais conhecidas abordagens, devida a Lombroso (1968), colocava como determinante da criminalidade as patologias individuais. Tal ênfase biológica nas causas do crime, contudo, foi abandonada após a Segunda Guerra em virtude do seu conteúdo racista, que condenava pessoas com determinadas características físicas a serem portadoras contínuas da doença da criminalidade.

Estando as teorias sobre as causas da criminalidade relacionadas ao aprendizado social, não é de se ad mirar que, historicamente, os sociólogos tenham dado grandes contribuições ao tema. Entretanto, há muito a questão da criminalidade vem também chamando a atenção de economistas, ainda que apenas a partir do final do século passado esse tenha sido um objeto central de seus estudos. Por exemplo, Adam Smith havia observado que crime e demanda por proteção ao crime são motivados ambos pela acumulação da propriedade. William Paley também elaborou uma cuidadosa análise a respeito de fa- 
tores que condicionariam as diferenças entre crime e sanções. Jeremy Bentham, por outro lado, conferiu especial importância ao cálculo do comportamento do criminoso e às respostas ótimas dadas pelas autoridades locais (ver Ehrlich, 1996).

De fato, um survey aplicado em 1901 nas universidades americanas (Tolman, 1902/1903) dava conta de que entre os primeiros cursos oferecidos sob a denominação genérica de "sociologia" já constavam currículos de criminologia e penologia. A esse respeito, apenas recentemente as universidades de economia americanas têm incluído em seus currículos o estudo do crime.

Uma teoria que explique o comportamento social, em particular as ações criminosas, deveria levar em conta pelo menos dois aspectos: $a$ ) a compreensão das motivações e do comportamento individual; $\mathrm{e} b$ ) a epidemiologia associada, ou como tais comportamentos se distribuem e se deslocam espacial e temporalmente (Cressey, 1968). De acordo com Cano e Soares (2002), é possível distinguir as diversas abordagens sobre as causas do crime em cinco grupos:

“a) teorias que tentam explicar o crime em termos de patologia individual; b) teorias centradas no homo economicus, isto é, no crime como uma atividade racional de maximização do lucro; $c$ ) teorias que consideram o crime como subproduto de um sistema social perverso ou deficiente; $d$ ) teorias que entendem o crime como uma conseqüência da perda de controle e da desorganização social na sociedade moderna; e e) correntes que defendem explicações do crime em função de fatores situacionais ou de oportunidades." (2002:3)

Objetivamos, nas próximas seções, elaborar um quadro resumido dessas muitas abordagens, ao mesmo tempo que buscamos fazer uma breve resenha bibliográfica sobre o tema. Nas conclusões, apresentaremos um quadro contendo os resultados de alguns dos principais estudos, as respectivas teorias que os inspiraram e as variáveis normalmente utilizadas para sua aferição.

\section{UM RESUMO DAS PRINCIPAIS ABORDAGENS SOBRE AS CAUSAS DA VIOLÊNCIA E DA CRIMINALIDADE}

\section{Teorias Focadas nas Patologias Individuais}

As teorias que explicam o comportamento criminoso a partir de patologias individuais poderiam ser divididas em três grupos: de nature- 
za biológica, psicológica e psiquiátrica. Esses desenvolvimentos se encontram no limiar da criminologia, sendo uma das abordagens mais conhecidas, conforme já salientado, aquela de Lombroso (1968), na qual a formação óssea do crânio e o formato das orelhas, entre outras características, constituiriam indicadores da patologia criminosa. Essa perspectiva lombrosiana inspirou ainda trabalhos no campo da psiquiatria, cuja hipótese era que criminosos seriam um tipo de indivíduo inferior, que se caracterizaria por desordens mentais, alcoolismo, neuroses, entre outras particularidades (Hakeem, 1958). Healy (1915), em The Individual Delinquent, acentuou uma série desses traços e fatores, considerados também por Glueck (1918) em um estudo com 608 detentos da prisão de Sing Sing. Sob a ótica psicológica, muitos trabalhos foram desenvolvidos logo após a Primeira Guerra, nos quais se tentava medir objetivamente o grau em que criminosos eram psicologicamente diferentes de não-criminosos. Supunha-se, então, que a baixa inteligência seria uma importante causa da criminalidade (Cressey, 1968).

Após a Segunda Guerra, tais teorias sobre as características psicológicas intrínsecas que criminosos teriam foram abandonadas, principalmente em função do seu conteúdo racista, além do que novos estudos e experimentos trataram de mostrar que não havia nenhuma distinção entre criminosos e não-criminosos, seja por grau de inteligência ou outro traço psicológico intrínseco. Em anos mais recentes, essas análises focadas nas patologias individuais se têm desenvolvido no sentido de conjugar as características biopsicológicas do indivíduo com seu histórico de vida pessoal e relações sociais. Daly e Wilson $(1983 ; 1988 ; 1999)$ destacam-se como estudiosos da corrente conhecida como biologia social. Por esta visão, o crime, particularmente o homicídio, decorreria da necessidade consciente ou inconsciente do indivíduo de preservar a sua linha genética. Essa hipótese explicaria por que haveria maiores taxas de filicídios ou de abusos de crianças por pais que não os biológicos (Cano e Soares, 2002). Com o avanço da genética, outra linha de conhecimento começou a desenvolver-se com a neurobiologia do crime. Entre os fatores apontados como relacionados à criminalidade, Pallone e Hennessy (2000) concluem por uma relação positiva entre portadores de neuropatologias e homicidas.

De modo geral, tanto biólogos como psicólogos têm se movido da idéia de que haveria disfunções ou desvios de características do cri- 
minoso em relação ao não-criminoso para a idéia de que a criminalidade se constituiria em uma espécie de ajustamento de problemas mentais ou biológicos que o indivíduo teria conectado a outros problemas derivados de relacionamentos sociais. Por essa perspectiva, esses estudos têm, crescentemente, se aliado a outras teorias de estrutura social e cultural para explicar a criminalidade. No momento em que escrevíamos este artigo, por exemplo, Moffie, da Universidade de Wisconsin, apontou que indivíduos com disfuncionalidades dos genes MAO A, responsáveis pela produção de uma enzima que atua sobre neotransmissores, e que possuam históricos de violência sofrida - principalmente na infância - representam um fator de risco para comportamento anti-social nove vezes maior do que o normal.

\section{Teoria da Desorganização Social}

Trata-se de uma abordagem sistêmica cujo enfoque gira em torno das comunidades locais, sendo estas entendidas como um complexo sistema de redes de associações formais e informais, de relações de amizade, parentesco e outras que, de alguma forma, contribuam para o processo de socialização e aculturação do indivíduo. Essas relações seriam condicionadas por fatores estruturais, como status econômico, heterogeneidade étnica e mobilidade residencial. Além destes, a teoria tem sido estendida para comportar outras variáveis, como fatores de desagregação familiar e urbanização. Sob esse ponto de vista, a organização social e a desorganização social constituiriam laços inextricáveis de redes sistêmicas para facilitar ou inibir o controle social (Sampson, 1997). Desse modo, a criminalidade emergiria como conseqüência de efeitos indesejáveis na organização dessas relações sociais comunitárias e de vizinhanças (Entorf e Spengler, 2002) como, por exemplo, redes de amizades esparsas, grupos de adolescentes sem supervisão ou orientação, ou baixa participação social.

O primeiro estudo empírico que procurou testar a teoria da desorganização social se deve a Sampson e Groves (1989), que trabalharam com dados longitudinais de 238 localidades na Grã-Bretanha, a partir de uma pesquisa de vitimização nacional com 10.905 residências. As regressões estimadas por mínimos quadrados dão grande suporte à teoria. Foram utilizadas como variáveis dependentes a prevalência de cinco tipos de crime (assaltos e roubos de rua, violência perpetrada por estranhos, arrombamentos e roubo auto-imputado e vandalismo) e mais o total de vitimizações. Foram testadas oito variáveis explicati- 
vas: status socioeconômico, heterogeneidade étnica, estabilidade residencial, desagregação familiar, urbanização, redes de amizade local, grupos de adolescentes sem supervisão e participação organizacional. Os fatores que resultaram em estatísticas significativas ao nível de 5\% mais importantes foram desagregação familiar, urbanização, grupos de adolescentes sem supervisão e participação organizacional.

Miethe et alii (1991) fizeram um painel com dados de registros policiais de 584 cidades norte-americanas para os anos de 1960, 1970 e 1980, de modo a testar as variáveis explicativas para homicídios, roubos e arrombamentos. Entre os fatores significativos figuravam a taxa de desemprego, a heterogeneidade étnica, a mobilidade residencial, o controle institucional e a existência de mais de um morador por cômodo.

Uma terceira estratégia de aferição empírica da supramencionada teoria foi implementada por Warner e Pierce (1993), que a partir de chamadas telefônicas para a polícia fizeram um cross-section de 1.980 localidades na vizinhança de Boston, em 1960. Uma versão alternativa do modelo levava em conta o efeito derivado da interação das variáveis explanatórias. Enquanto a pobreza teve um coeficiente significativo e com o sinal esperado pela teoria, a mobilidade residencial gerou um sinal contrário ao esperado e a heterogeneidade na maioria dos modelos testados resultou em não significativa, destoando dos trabalhos anteriores. No trabalho de Smith e Jarjoura (1988), com dados longitudinais provenientes de pesquisa de vitimização, a mobilidade apareceu como não significativa para explicar a criminalidade.

Vários outros estudos procuraram demonstrar o sentido contrário da causalidade, ou seja, os efeitos adversos que a criminalidade gera sobre a organização social. Destacam-se aí os trabalhos de Skogan (1986; 1991), Bursik (1986), Katzman (1980), Sampson e Wooldredge (1986).

A conclusão geral que se poderia extrair de todos esses estudos seria a favor de uma relação negativa entre crime e coesão social. Segundo Sampson (1995:203): "crime itself can lead to simultaneous demografic collapse and a weakening of the informal control structures and mobilization capacity of communities, which in turn fuel[s] further crime" ["o crime por si só pode conduzir a um simultâneo colapso 
demográfico e um esgarçamento das estruturas de controle informais e capacidade de mobilização das comunidades que, por seu turno, levariam a mais crimes", tradução do autor].

\section{Teoria do Estilo de Vida}

Essa abordagem assume como hipótese implícita a existência de três elementos: uma vítima em potencial, um agressor em potencial e uma tecnologia de proteção ditada pelo estilo de vida da vítima em potencial. Nesse caso, quanto maior a provisão de recursos por proteção, maiores os custos de se perpetrar o crime e menores as oportunidades para o agressor. Desse modo, indivíduos que possuem atividades de lazer dentro de casa, relativamente àqueles que costumam divertir-se em ambientes públicos, tenderiam a ser menos vitimados. Da mesma forma, pessoas que trabalham fora ou que moram sozinhas também teriam maiores probabilidades de ser vitimadas, em relação àquelas que ou não trabalham ou trabalham em casa ou ainda àquelas que moram com outros familiares.

Devemos observar, entrementes, que tal perspectiva não constitui, stricto sensu, uma teoria de causação do crime. Isto porque, conforme já salientamos, qualquer teoria desse tipo deveria levar em conta a compreensão das motivações e do comportamento individual e a epidemiologia associada, ou como tais comportamentos se distribuem e deslocam espacial e temporalmente. Essa abordagem não considera nenhum desses dois eixos e seu foco é direcionado para os hábitos e a rotina de vida das vítimas. Certamente, quanto maiores as facilidades que a vítima em potencial venha a oferecer, maiores serão as chances de haver um delinqüente disposto a perpetrar o crime. No limite, o arcabouço teórico do estilo de vida aproxima-se mais de uma tautologia do que propriamente de uma teoria. Uma questão vital que não é considerada na "teoria do estilo de vida", mas que certamente é uma hipótese implícita, diz respeito ao comportamento maximizador e racional do criminoso ao escolher as suas vítimas, segundo a oportunidade e os baixos custos de operacionalizar a ação. Contudo, como o comportamento do criminoso não é posto em questão, se poderia mesmo gerar interpretações bastante controversas, para não dizer absurdas, de que a responsabilidade sobre o delito terminaria recaindo sobre a vítima, na medida em que a mesma "deveria" ter um comportamento mais conservador, a fim de evitar o crime. Nesse sentido, a população não sair à rua, por exemplo, certamente, levaria a uma diminuição da 
criminalidade. Contudo, não se esclarece com tal fato as causas que levam alguns indivíduos a cometer crimes e como estes podem se difundir na sociedade e, tampouco, se se obteria com tais constatações (óbvias) pistas para a elaboração de políticas de segurança pública.

Normalmente, os trabalhos empíricos que procuraram aferir a relação entre o estilo de vida e a criminalidade utilizaram pesquisas de vitimização. Várias pesquisas obtiveram êxito no sentido de mostrar essa relação empiricamente, cabendo destaque aos trabalhos de Messner e Blau (1987), Miethe et alii (1991), Roncek e Maier (1991), Miethe et alii (1987), Osgood et alii (1996) e Tremblay e Tremblay (1998)².

\section{Teoria da Associação Diferencial (Teoria do Aprendizado Social)}

Essa abordagem, inaugurada por Sutherland (1973), centra seu foco de análise no processo pelo qual os indivíduos, principalmente os jovens, determinavam seus comportamentos a partir de suas experiências pessoais com relação a situações de conflito. O comportamento favorável ou desfavorável ao crime seria apreendido a partir das interações pessoais, com base no processo de comunicação. Nesse sentido, a família, os grupos de amizade e a comunidade ocupam papel central. Contudo, os efeitos decorrentes da interação desses atores são indiretos, cujas influências seriam captadas pela variável latente "determinação favorável ao crime (DEF)", uma vez que esta não pode ser mensurada diretamente mas, sim, resulta da conjunção de uma série de outras. Dentre as variáveis mensuradas normalmente utilizadas para captar essa variável latente DEF estão: grau de supervisão familiar; intensidade de coesão nos grupos de amizade; existência de amigos que foram, em algum momento, pegos pela polícia; percepção dos jovens acerca de outros jovens na vizinhança que se envolvem em problemas; e se o jovem mora com os pais.

Matsueda (1982) foi o principal autor que buscou elementos empíricos para atestar a teoria da associação diferencial, a partir de 1.140 entrevistas individuais. Outros artigos importantes nesse campo são de Bruinsma (1992) e McCarthy (1996) que, além de encontrarem evidências favoráveis à existência da variável latente $\mathrm{DEF}$, enfatizaram o fato de que o que também motiva e legitima tal comportamento é o contato e o aprendizado em métodos e técnicas criminosos. 


\section{Teoria do Controle Social}

Ao contrário das demais teorias que procuram explicar o que leva pessoas a cometer crimes, a presente abordagem busca entender por que algumas se abstêm de cometê-los. Nesse sentido, a questão aqui é explicar as razões que levam o cidadão a ser dissuadido de trilhar o caminho do crime. O enfoque utilizado - ao contrário da teoria do homem econômico, por exemplo, de que tais elementos dissuasórios seriam consubstanciados na probabilidade de o criminoso ser descoberto cometendo o delito e o custo associado à respectiva punição baseia-se inteiramente na idéia do controle social, a partir do sentido de ligação que a pessoa tem com a sociedade ou, dito de outra forma, a partir da crença (e concordância) dessa pessoa no trato ou acordo social. Desse modo, quanto maior o envolvimento do cidadão no sistema social, quanto maiores forem os seus elos com a sociedade e maiores os graus de concordância com os valores e normas vigentes, menores seriam as chances de esse ator se tornar um criminoso.

Do ponto de vista da literatura empírica, normalmente, procura-se aferir a teoria do controle social por meio de pesquisas domiciliares, que fornecem informações para a elaboração de modelos de variáveis latentes, uma vez que atributos como "acordos", "crenças nos valores" etc. são sempre mensurados de maneira indireta. Muitos desses modelos empíricos foram orientados para explicar mais especificamente a delinqüência juvenil, como foi o caso de Agnew (1991), que utilizou as seguintes variáveis.

No que se refere aos trabalhos empíricos desenvolvidos sob a orientação do "controle social", enquanto Agnew (1991) não encontrou evidências fortes que corroborem a teoria, outros estudos têm concluído por sua atestação -, principalmente no que se relaciona com as variáveis "ligações e afeições familiares" e "compromissos escolares" -, dentre os quais se destacam os de Agnew e White (1992), Agnew (1993), Paternoster e Mazerolle (1994), Junger-Tas (1992) e Horney et alii (1995). Este último se diferencia dos demais por utilizar dados de entrevistas com encarcerados em vez de dados com informações auto-reportadas ou entrevistas com jovens.

\section{Teoria do Autocontrole}

Segundo Gottfredson e Hirschi (1990), que elaboraram a teoria do autocontrole, o que diferenciaria os indivíduos que têm comportamen- 
Quadro 1

Variáveis Normalmente Utilizadas em Modelos de Controle Social

\begin{tabular}{|c|c|}
\hline Variáveis latentes & Questões constantes da pesquisa primária \\
\hline 1. Ligação filial & $\begin{array}{l}\text { - Você normalmente faz muitas atividades com a família? } \\
\text { - Você fala sobre qualquer assunto com seus pais? } \\
\text { - Você se dá bem com seus pais? }\end{array}$ \\
\hline 2. Ligação escolar & $\begin{array}{l}\text { - Professores não me dirigem a palavra em sala, ainda que eu le- } \\
\text { vante a mão. } \\
\text { - Freqüentemente eu sinto que ninguém liga para mim na escola. } \\
\text { - Eu não sinto como se realmente pertencesse à escola. } \\
\text { - Ainda que eu saiba que existem várias crianças ao meu redor, } \\
\text { freqüentemente eu me sinto sozinho na escola. }\end{array}$ \\
\hline 3. Compromisso & $\begin{array}{l}\text { - Você está se saindo bem na escola, ainda que tenha dificuldades } \\
\text { com a matéria? } \\
\text { - Você tem uma média escolar alta? }\end{array}$ \\
\hline $\begin{array}{l}\text { 4. Crenças } \\
\text { desviantes }\end{array}$ & $\begin{array}{l}\text { - Quão errado é: alguém da sua idade destruir ou estragar pro- } \\
\text { positalmente algo que não lhe pertença? } \\
\text {... furtar algo com valor inferior a US\$ } 5 \text { ? } \\
\text {... bater ou ameaçar bater em alguém sem razão? } \\
\text {... furtar algo com valor superior a US } \$ 50 ?\end{array}$ \\
\hline $\begin{array}{l}\text { 5. Amigos } \\
\text { delinqüentes }\end{array}$ & $\begin{array}{l}\text { - Durante o ano passado, quantos de seus amigos mais próxi- } \\
\text { mos: destruíram ou estragaram propriedades alheias? } \\
\text {... furtaram algo com valor inferior a US\$ } 5 ? \\
\text {... bateram ou ameaçaram bater em alguém sem razão? } \\
\text {... furtaram algo com valor superior a US\$ } 50 ?\end{array}$ \\
\hline
\end{tabular}

Fonte: Entorf e Spengler (2002).

tos desviantes ou vícios (jogos de azar, promiscuidade sexual, fumo, drogas, álcool etc.) de outros é o fato de os primeiros não terem desenvolvido mecanismos psicológicos de autocontrole na fase entre os 2 ou 3 anos até a fase pré-adolescente. Tal "anormalidade" decorreria de deformações no processo de socialização da criança, desencadeadas pela ineficácia na conduta educacional ministrada pelos pais, que falharam em não impor limites à criança, seja em conseqüência da falta de uma supervisão mais próxima, seja por negligenciarem eventual malcomportamento da criança, não impondo punições relativas à mesma, endossando assim seu comportamento egoísta. Como resultante da má-formação desse mecanismo de autocontrole, o indivíduo, a partir da adolescência, passa a exibir uma persistente tendên- 
cia a agir baseado exclusivamente em seus próprios interesses, com vistas à obtenção de prazer imediato, sem considerar eventuais conseqüências de longo prazo e os impactos de suas ações sobre terceiros.

Em vista da impossibilidade de se mensurar diretamente a variável autocontrole, mais uma vez o método freqüentemente utilizado nos estudos empíricos que procuram sustentar essa abordagem é o de variáveis latentes, obtidas com base na aplicação de questionários. Alguns exemplos de questões normalmente encontradas nesses questionários dizem respeito à concordância em relação às frases: "freqüentemente eu ajo ao sabor do momento"; "eu raramente deixo passar uma oportunidade de gozar um bom momento"; "eu olho para mim mesmo, ainda que eu faça coisas que colocam as pessoas em dificuldades" etc.

Gibbs et alii (1998), Arneklev et alii (1993) e Polakowski (1994) foram alguns dos estudiosos que mais se notabilizaram nesse campo, tendo encontrado, ainda que parcialmente, evidências em favor da teoria do autocontrole para explicar a delinqüência.

Contudo, há que se aduzir duas críticas a essa abordagem. Do ponto de vista teórico, a capacidade de uma única variável explicar um conjunto tão grande de comportamentos desviantes sempre coloca em dúvida toda a teoria, por ser genérica demais. Por outro lado, os trabalhos empíricos, normalmente baseados em entrevistas individuais, estão à procura de evidências de falta de autocontrole. A correlação de indícios de ausência de autocontrole com o comportamento desviante, nesse caso, parece mais tautológica do que uma possível explicação para a delinqüência. Por definição, o delinqüente é aquele que desrespeita os direitos alheios para satisfazer suas necessidades ou vontades pessoais. Desse modo, evidências da teoria, a partir da constatação de que delinqüentes possuem determinados atributos de comportamento relacionados à variável latente autocontrole, parecem não ter nenhum sentido causal. Talvez, um modo adequado de testar a teoria (porém, extremamente complicado do ponto de vista prático) seja por meio de comparações de grupos de amostra de controle em dois períodos distintos: uma amostra de crianças educadas por pais permissivos controlada por outra em que a educação para a socialização da criança se dê de forma a impor limites, sendo estas 
amostras acompanhadas nos períodos seguintes, na adolescência e no período adulto.

\section{ANOMIA}

Uma das mais tradicionais explicações de cunho sociológico acerca da criminalidade é a teoria da anomia, de Merton (1938). Segundo esse arcabouço teórico, a motivação para a delinqüência decorreria da impossibilidade de o indivíduo atingir metas desejadas por ele, como, por exemplo, o sucesso econômico. Cohen (1955), por sua vez, estendeu a abordagem para compreender a questão do status social. A necessidade de operacionalizar essa teoria, ou de elaborar variáveis ou questões que traduzam o sentido da mesma, fez com que surgissem três perspectivas distintas quanto à sua aferição, que encaram a questão a partir de: a) diferenças das aspirações individuais e os meios econômicos disponíveis, ou expectativa de realização; $b$ ) oportunidades bloqueadas (Agnew, 1987; Burton Jr. e Cullen, 1992); e c) privação relativa (Burton Jr. et alii, 1994).

Apesar de as diferenças entre as três perspectivas serem bastante sutis, a escolha de uma delas tem implicações diretas nas questões específicas relacionadas no questionário de entrevista. Sob a primeira perspectiva, o processo de anomia ou tensão decorreria da diferença entre as aspirações individuais e as reais possibilidades de realização das mesmas. Um exemplo de questão que poderia indicar a existência desse fenômeno seria: "eu gostaria de possuir um carro, uma casa, um tênis da moda etc. Mas eu acho que não conseguirei dinheiro ou condições para satisfazer tais aspirações". Sob a segunda ótica, o foco de divergências com as normas instituídas passa a existir a partir do momento em que o indivíduo percebe que o seu insucesso decorre de condições externas à sua vontade, o que implicaria afirmações do tipo: "toda vez que tento ir pra frente, algo me segura" ou "eu não tenho sucesso, pois não participo de uma rede de conexões". Já a privação relativa dá ênfase à distância entre o ideal de sucesso da sociedade (vivido por alguns) e aquela situação específica em que o indivíduo se encontra. Um exemplo seria: "sinto-me irritado com o fato de alguns terem muito, ao passo que não possuo o suficiente para viver adequadamente".

Várias pesquisas têm procurado encontrar evidências empíricas em favor da relação entre anomia e criminalidade. Contudo, parece ser 
uma norma o fato de que elas não conseguiram lograr êxito (ver Entorf e Spengler, 2002:56). Alguns dos trabalhos que mais se notabilizaram nesse campo foram os de Burton Jr. et alii (1994), Reiss e Rhodes (1963), Elliot e Voss (1974), Greenberg (1977), Agnew (1984) e Blau e Blau (1982).

Mais recentemente, Agnew (1992) procurou ampliar a teoria da anomia para compreender - além da frustração decorrente da defasagem entre as aspirações individuais e os meios socialmente existentes para satisfazê-las -, adicionalmente, duas circunstâncias: a frustração derivada do fato de outros terem retirado do indivíduo algo de valor (não estritamente material); e o fato de que as pessoas são confrontadas com circunstâncias negativas engendradas por discordâncias ou divergências sociais. Esse desenvolvimento, que ficou conhecido como Teoria Geral da Anomia (General Strain Theory), foi testado por Agnew e White (1992), Agnew (1993), Paternoster e Mazerolle (1994) e Hoffmann e Miller (1998), e todos encontraram evidências empíricas a favor. De maneira geral, esses trabalhos foram baseados em dados provenientes de pesquisas individuais, nas quais várias categorias de crimes e contravenções foram explicadas a partir de variáveis indicadoras de focos de tensão social. Alguns exemplos são: "distância entre aspirações individuais e expectativas", "oportunidades bloqueadas"; "frustração relativa"; "eventos de vida negativos"; "sofrimento cotidiano"; "relações negativas com adultos"; "brigas familiares"; "desavenças com vizinhos"; e "tensões no trabalho".

\section{TEORIA INTERACIONAL}

Segundo Thornberry (1996 apud Entorf e Spengler, 2002), a proposição do modelo interacional é que o comportamento desviante ocorre em um processo interacional dinâmico. Desse modo, mais do que perceber a delinqüência como uma conseqüência de um conjunto de fatores e processos sociais, a perspectiva interacional procura entendê-la simultaneamente como causa e conseqüência de uma variedade de relações recíprocas desenvolvidas ao longo do tempo. Entorf e Spengler (2002) destacam que há dois elementos importantes sustentando essa abordagem: a perspectiva evolucionária e os efeitos recíprocos. A primeira consubstancia-se na presunção de que o crime não é uma constante na vida do indivíduo, mas um processo em que a pessoa inicia sua atividade criminosa em torno dos 12 ou 13 anos (iniciação), aumenta o seu envolvimento em tais ações por volta dos 16 ou 17 anos 
(desenvolvimento) e finaliza esse processo até os 30 anos. Os efeitos recíprocos dizem respeito às virtuais endogeneidades das variáveis explicativas entre si e delas com relação ao que se deseja explicar ${ }^{3}$. Os modelos interacionais inspiram-se normalmente nas teorias da associação diferencial e do controle social, que sugerem as variáveis a serem utilizadas, como, p. ex.: ligação com os pais, notas, envolvimento escolar, grupos de amizade, punição paternal para desvios, ligação com grupos delinqüentes etc.

Thornberry elaborou um survey contendo as discussões acerca de dezessete estudos interacionais que ele identificou. Dentre estes, dezesseis trabalhos encontraram uma relação bidirecional entre as variáveis explicativas e o comportamento delinqüente, comprovando a importância do efeito feedback proposto pela teoria. Além disso, nove desses estudos evidenciaram uma forte relação entre o comportamento delinqüente e a amizade com grupos delinqüentes, o que, por outro lado, confirma a importância da teoria do aprendizado social para a compreensão dos processos criminológicos.

\section{TEORIA ECONÔMICA DA ESCOLHA RACIONAL}

Gary Becker (1968), com o artigo seminal "Crime and Punishment: An Economic Approach", impôs um marco à abordagem sobre os determinantes da criminalidade ao desenvolver um modelo formal em que o ato criminoso decorreria de uma avaliação racional em torno dos benefícios e custos esperados aí envolvidos, comparados aos resultados da alocação do seu tempo no mercado de trabalho legal. Basicamente, a decisão de cometer ou não o crime resultaria de um processo de maximização de utilidade esperada, em que o indivíduo confrontaria, de um lado, os potenciais ganhos resultantes da ação criminosa, o valor da punição e as probabilidades de detenção e aprisionamento associadas e, de outro, o custo de oportunidade de cometer crime, traduzido pelo salário alternativo no mercado de trabalho.

Vários artigos que se seguiram, ainda com uma abordagem da escolha racional, basicamente, trabalharam com inovações em torno da idéia já estabelecida por Becker, em que dois vetores de variáveis estariam condicionando o comportamento do potencial delinqüente. De um lado, os fatores positivos (que levariam o indivíduo a escolher o mercado legal), como o salário, a dotação de recursos do indivíduo etc.; de outro, os fatores negativos, ou dissuasórios (deterrence), como 
a eficiência do aparelho policial e a punição. Dentre esses estudos, cabe destaque para os de Ehrlich (1973), Block e Heinecke (1975) e Leung (1995).

Um ponto interessante a observar é que, a despeito de o modelo supramencionado ser de natureza microeconômica, cujo foco recai sobre os determinantes individuais da criminalidade, quase todas as pesquisas empíricas foram construídas a partir de uma estrutura de dados agregados regionalmente. Certamente, isso deve ser resultado da indisponibilidade de dados individualizados necessários para a aferição do modelo de escolha racional. O custo dessa estratégia é a introdução da hipótese de que o criminoso atua na mesma região em que reside. Nesse ponto, surge um dilema: quanto menor for essa unidade geográfica, mais inverossímil tende a ser a hipótese; quanto maior for essa unidade geográfica, mais informações se perdem nas médias agregadas.

Ehrlich (1973) estendeu a análise de Becker para considerar qual deveria ser a alocação ótima do tempo em torno do mercado criminoso ou legal. Ainda, o autor investigou os efeitos decorrentes da distribuição de renda sobre o crime. Mais especificamente com relação aos crimes contra a propriedade, ele assinalou que um elemento determinante seria a oportunidade oferecida pelas vítimas potenciais. Ehrlich adotou como medidas dessa oportunidade oferecida: $a$ ) a renda mediana das famílias de determinada comunidade; e $b$ ) o percentual de famílias que recebem até o primeiro quartil da renda da comunidade. Utilizando informações do Uniform Crime Report - UCR de 1940, 1950 e 1960, o autor estabelece uma relação positiva significativa entre as medidas de desigualdade enunciadas e vários tipos de crime.

Block e Heinecke (1975) argüiram que uma vez que existem diferenças éticas e psicológicas envolvidas no processo de decisão do indivíduo entre os setores legal e ilegal, o problema da oferta de crimes deveria ser formulado em termos de uma estrutura de preferências multifatorial, que levasse em conta outros aspectos que não apenas a renda. Eles mostraram que os resultados de Becker e Ehrlich, acerca das oportunidades de ganho no mercado legal, são válidos apenas se existirem equivalentes monetários das atividades legal e ilegal e se estes forem independentes do nível de riqueza. 
Zhang (1997), baseado na inspiração teórica de Block e Heinecke (1975) - de que a alocação ótima do tempo do indivíduo dependeria, além dos custos e benefícios alternativos associados aos mercados legais e ilegais, do nível de riqueza do indivíduo -, desenvolveu um modelo formal de modo a incluir entre as variáveis que condicionariam o crime a existência de programas sociais que possibilitariam ao indivíduo acesso a um patamar mínimo de bem-estar. Com base no UCR de 1987, o autor, utilizando dados dos estados, procurou explicar os crimes contra a propriedade valendo-se de três outros conjuntos de variáveis, entre as quais as de natureza econômica, as relacionadas à existência de programas sociais e as de "repressão judicial" (deterrence), controlados por outras características da população. As variáveis utilizadas foram: desigualdade; desemprego; probabilidade de detenção; prisão e condenação; tamanho da sentença; os pagamentos sociais per capita do estado; número de beneficiários dos programas dividido pela população do estado; e razão entre os benefícios máximos de famílias com crianças dependentes ${ }^{4}$ e a ajuda-padrão para uma família com três membros. Os resultados mostraram que as três últimas variáveis, que estariam condicionando um nível mínimo de bem-estar à população local, são negativas e significativas para várias especificações das equações.

Vários autores procuraram ainda incorporar a idéia do histórico criminal, condicionando as decisões ótimas do indivíduo a favor do crime, o que explicaria um processo de "inércia criminal" - à medida que o indivíduo opta pela carreira criminal, menores são as probabilidades de ele sair do crime e ajustar-se ao mercado de trabalho legal. Segundo Leung (1995), os antecedentes criminais diminuiriam os retornos futuros esperados no mercado legal em decorrência de dois elementos: o estigma que o indivíduo passa a sofrer da sociedade (ainda mais se é ex-apenado); e a depreciação do capital humano condicionada pela perda natural das habilidades anteriores e pela ausência de investimento em educação e treinamento profissional durante o período em que o mesmo se encontrava alocando seu tempo a atividades criminosas ou encarcerado.

Mais recentemente, os estudos de orientação "econômica" têm procurado incorporar outros ingredientes para explicar o processo de decisão do indivíduo quanto a ingressar no crime ou não, além das inúmeras medidas tradicionais de benefícios e custos esperados do ofensor, tangenciando questões que, até então, eram discutidas eminente- 
mente pelos sociólogos, como a das interações sociais e a do aprendizado social ${ }^{5}$. As interações sistêmicas foram introduzidas nos modelos econômicos por Sah (1991) e Posada (1994). A idéia básica era que índices de criminalidade maiores, em determinada região, para um determinado dispêndio em segurança pública, levariam à percepção, por parte do ofensor, de haver uma probabilidade menor de aprisionamento. Nesse caso, o aumento exógeno nos índices de criminalidade de determinada região só seria revertido por meio de um maior dispêndio de recursos com segurança.

Anteriormente, abordamos a teoria do aprendizado social em que Sutherland (1973) considerou que os indivíduos determinavam seus comportamentos a partir de experiências pessoais em situações de conflito. Essas determinações de comportamentos favoráveis ou desfavoráveis ao crime seriam apreendidas a partir das interações pessoais e com base no processo de comunicação. Glaeser e Scheinkman (1996) deram ênfase também a essa questão do aprendizado social, mas argumentaram que tais "transferências de informações" entre os agentes de uma determinada comunidade, acerca de comportamentos e técnicas criminosos, determinavam o custo do crime, seja pelo conhecimento de tecnologia, seja pelo custo moral, na medida em que tais interações, se em um ambiente criminoso, levariam a uma diminuição do controle social.

Vários outros estudos empíricos sob orientação da escolha racional foram feitos, em que se investigou a relação do crime com o mercado de trabalho, a renda, a desigualdade, a dissuasão policial, a demografia e a urbanização, entre outras variáveis. Alguns trabalhos que poderiam ser destacados nesse meio são os de Wolpin (1978), Freeman (1994), Fajnzylber et alii (1998), Gould et alii (2000) e Entorf e Spengler (2000).

Freeman (1994), por exemplo, fez um exaustivo survey sobre os trabalhos empíricos envolvendo mercado de trabalho e crime. Basicamente, no que diz respeito aos estudos de séries temporais, ele constatou não haver consenso sobre a questão ${ }^{6}$. Já os estudos que utilizaram técnicas de análises longitudinais com dados agregados regionalmente, em geral, conseguiram captar a relação positiva entre crime e desemprego, a despeito do clássico problema de existência de correlações espúrias. Os estudos que obtiveram maior êxito na demonstração de eventuais relações entre crime e mercado de trabalho foram aqueles 
desenvolvidos em cross-section com dados individualizados do perpetrador, uma vez que os mesmos enfocam mais precisamente as circunstâncias sob as quais a decisão foi tomada. Críticas também estão associadas a tais trabalhos, que se relacionam aos dados disponíveis. Estes, normalmente, ou são provenientes de encarcerados - e a amostra, por si, é viesada - ou são derivados de entrevistas do tipo self-reported criminal, que embute o problema de que muitos crimes podem não estar sendo revelados pelos entrevistados. Desses estudos, a evidência mostra que os presos apresentam maior probabilidade de ter menos renda ou menos emprego que outros grupos. Tauchen et alii (1994), por exemplo, verificaram que jovens empregados há menos tempo do que outros têm probabilidade maior de serem presos. Por outro lado, os dados podem estar refletindo o fato de detidos serem mais inaptos para o sucesso na sociedade por causa de características pessoais.

Desse modo, não seria a precariedade do mercado de trabalho o fator determinante do crime, e sim a decorrência de atributos pessoais e individuais. Nesse caso, políticas pró-labore teriam pouco impacto sobre o crime. Três abordagens diferentes podem dirimir tais dúvidas: observar a mesma pessoa em dois momentos diferentes, com emprego e sem emprego; observar a relação do comportamento criminoso individual com as características da área, no que diz respeito à taxa de desemprego e renda; e estimar a oferta de trabalho, a participação criminal, salários previstos e rentabilidade do crime. Em qualquer uma dessas vias, contudo, as abordagens esbarram no mesmo problema de ausência de dados.

Gould et alii (2000) exploraram também a relação das oportunidades no mercado de trabalho com o crime. Os autores analisaram um painel com efeitos fixos envolvendo 709 municípios americanos, de 1979 a 1997, utilizando dados do UCR sobre vários tipos de crime contra a pessoa e contra a propriedade. Três interessantes inovações foram feitas nesse estudo: analisaram os resultados sobre o segmento do mercado de trabalho não especializado (melhor do que sobre o mercado como um todo); em vez de se concentrarem apenas no desemprego, observaram também os salários reais dos não especializados; e desagregaram o mercado de trabalho para enfocar especificamente os jovens. Os resultados estatisticamente significativos apontaram que homens jovens não especializados respondem ao custo de oportunidade do crime. Para controlar uma possível endogeneidade, foram 
utilizadas variáveis instrumentais baseadas na composição industrial da área, tendência industrial agregada e mudanças demográficas dentro das indústrias no nível agregado. Os resultados deram conta ainda de que a tendência de longo prazo do crime pode ser mais bem explicada pela tendência de longo prazo dos salários de homens jovens não educados - que explica $43 \%$ e $53 \%$ dos crimes contra a propriedade e violentos contra a pessoa, respectivamente - do que pelo desemprego. A pesquisa não encontrou, por outro lado, evidências de que condições econômicas (mais especificamente relacionadas ao mercado de trabalho) afetam o crime, no que diz respeito à parcela da população com educação especializada (educada).

Outro estudo que merece destaque é o de Wolpin (1978), não apenas por trabalhar com uma longa série temporal de dados - que cobre seis tipos diferentes de crime ocorridos na Inglaterra e no País de Gales, desde 1894 a 1967 -, mas por utilizar seis variáveis diferentes de dissuasão judicial (o que é extremamente difícil de obter, mesmo nos países desenvolvidos), que incluem: taxa de esclarecimento do crime; taxa de condenação; taxa de aprisionamento; taxa de multa; taxa de reconhecimento; e tempo de sentença média. Dentre essas variáveis dissuasórias, as que se mostraram mais importantes e estatisticamente significativas foram a taxa de esclarecimento seguida da taxa de aprisionamento. Surpreendentemente, a variável punição resultou em estatísticas não significativas em todas as regressões geradas. Quanto aos efeitos decorrentes do desemprego e de maiores proporções de jovens na população, o estudo captou uma relação positivamente significativa, replicando os resultados já encontrados por Ehrlich (1973).

Entorf e Spengler (2000) fizeram um estudo em painel para a Alemanha, utilizando informações dos estados federativos, para o período 1975-1996. Os autores trabalharam com oito tipos diferentes de crime, entre os quais, crimes contra a pessoa e crimes contra a propriedade. Como regressores utilizaram além da taxa de esclarecimento do crime, o Produto Nacional Bruto - PNB per capita (como proxy para a oportunidade de renda ilegal), a diferença do PNB per capita da Alemanha em relação ao estado em questão (como medida de renda no mercado legal) e a taxa de desemprego. Os resultados mostraram haver relação negativamente significativa para a variável dissuasória (deterrence), ambigüidade para a variável desemprego e maior robustez para as variáveis renda e renda relativa no que diz respeito aos cri- 
mes contra a propriedade, replicando mais uma vez os resultados de Ehrlich (1973).

A importância do trabalho de Fajnzylber et alii (1998) se dá não apenas pela utilização de uma base de dados envolvendo até 128 países, mas porque os autores conseguem extrair da literatura estatísticas significativas e com o sinal esperado para diversas variáveis utilizadas, o que é, até certo ponto, surpreendente se imaginarmos tratar-se de países culturalmente tão heterogêneos e de dados agregados nacionalmente, o que implica, necessariamente, perda de informações, já que, segundo as várias teorias, grande parte dos determinantes da criminalidade ocorre localmente e a partir das interações comunitárias. Os dados utilizados relativos a homicídios e roubos, que cobrem o período 1970-1994, foram provenientes da United Nations World Crime, cujas informações são fornecidas pelos Ministérios da Justiça dos respectivos países. Os autores desenvolveram, sob a inspiração do modelo da escolha racional, um painel a partir do método de momentos generalizados [GMM]. Entre as variáveis explicativas estatisticamente significativas e com sinal negativo incluem-se a taxa de crescimento do Produto Interno Bruto - PIB, a probabilidade de aprisionamento e de severidade do sistema judicial e o nível de capital social, medido pelo grau de confiança nos World Value Surveys ${ }^{7}$. Com sinal positivo, resultaram: o índice de Gini, a taxa de criminalidade defasada um período, a existência de produção e consumo de drogas no país, o grau de urbanização e o grau de polarização na distribuição de renda. Já o PIB e a escolaridade média da população não deram resultados significativos, o que é coerente com os desenvolvimentos teóricos já que, até onde se tem conhecimento, não há consenso sobre o sinal da derivada parcial dessas duas variáveis.

\section{A LITERATURA BRASILEIRA}

Os estudos empíricos relacionados aos determinantes da criminalidade no Brasil sofrem de extrema limitação derivada da inexistência quase que absoluta de dados minimamente confiáveis, com cobertura nacional e reproduzidos temporalmente. Tais estudos começaram a ganhar ênfase com os trabalhos de Coelho (1988) e de Paixão (1988), em Minas Gerais, que criticavam a importância de fatores socioeconômicos na determinação da criminalidade, em detrimento de variáveis mais relacionadas à eficácia do sistema de justiça criminal, principalmente no que diz respeito à polícia. No Rio de Janeiro, Zaluar 
(1985), com seu trabalho pioneiro baseado em pesquisas etnográficas em favelas e comunidades, verificou uma série de elementos que associariam o contexto social nessas comunidades aos fenômenos da violência e criminalidade, lançando luz sobre a questão.

Um dos primeiros trabalhos quantitativos empíricos coube a Pezzin (1986), que desenvolveu uma análise em cross-section (com dados de 1983) e outra em séries temporais, para a região metropolitana de São Paulo (com dados compreendidos entre 1970 e 1984). Ele encontrou uma correlação positiva significativa entre urbanização, pobreza e desemprego em relação a crimes contra o patrimônio. Não houve evidências acerca da correlação entre estas variáveis sociais e demográficas em relação aos crimes contra a pessoa.

Beato e Reis (2000) tentaram evidenciar a relação defasada entre emprego e crimes violentos e crimes violentos contra a propriedade em Belo Horizonte entre 1996 e 1998. Seus resultados não foram significativos, reflexo, possivelmente, da curta série de dados estudada.

Sapori e Wanderley (2001) também tentaram evidenciar a relação entre emprego e homicídios nas regiões metropolitanas do Rio de Janeiro, São Paulo, Belo Horizonte e Porto Alegre, e também para roubos no caso de São Paulo. Os mesmos cruzaram dados provenientes da Pesquisa Mensal de Emprego - PME/IBGE de 1982 até 1998, com aqueles do Ministério da Saúde. Segundo os autores: “[...] Não foram encontrados indícios consistentes de que as variações das taxas de desemprego implicariam variações presentes ou futuras dos índices de violência, inevitavelmente. Os resultados não foram robustos."

Andrade e Lisboa (2000), utilizando os dados de homicídios do Ministério da Saúde (Sistema de Informações sobre Mortalidade SIM/Departamento de Informática do Sistema Único de Saúde - Datasus) para São Paulo, Minas Gerais e Rio de Janeiro, entre 1991 e 1997, desenvolveram um modelo logit, com base nas probabilidades de vitimização por idade. A análise dos autores por coortes permitiu-os identificar uma relação negativa estatisticamente significativa entre homicídios e salário real, principalmente para os jovens entre 15 e 19 anos; e uma relação positiva com a desigualdade, para faixas etárias inferiores a 20 anos. Os autores ainda encontraram um sinal negativo (significativo) entre desemprego e crime (para jovens), replicando um resultado idêntico ao de Land, Cantor e Russell (1994) para os 
Estados Unidos. Por último, a metodologia adotada permitiu encontrar evidências acerca do efeito da inércia criminal, na medida em que gerações que têm maior incidência de homicídios quando jovens tendem a perpetuar as maiores probabilidades de vitimização pelo resto da vida.

Cano e Santos (2001), com base em regressão estimada por OLS [Ordinary Last Square] para o ano de 1991, mostraram evidências acerca de uma correlação positiva entre taxas de urbanização e taxas de homicídios nos estados brasileiros, ao mesmo tempo que não puderam evidenciar a relação destas últimas com a desigualdade de renda ( $\mathrm{L}$ de Theil) e educação (o componente educativo do Índice de Desenvolvimento Urbano).

Mendonça (2000) desenvolve uma extensão do modelo da escolha racional de modo a introduzir a idéia de "insatisfação" na função utilidade, consubstanciada pela diferença entre o consumo corrente e uma cesta de consumo ideal. Em seu trabalho empírico, essa "insatisfação" seria medida a partir do coeficiente de Gini. Utilizando os dados de homicídios do Ministério da Saúde, entre 1985 e 1995, o autor desenvolveu um painel em que a determinante mais importante (significativa estatisticamente) foi a taxa de urbanização, seguida pela desigualdade de renda em um primeiro plano, e a renda média das famílias e o desemprego em um segundo, tendo todas essas variáveis os sinais esperados segundo a teoria. Em relação aos gastos públicos com segurança, os resultados não foram significativos.

Cerqueira e Lobão (2003) desenvolveram um modelo de produção de crimes que considera a existência de virtuais criminosos que objetivam a maximização de lucro e se defrontam com uma tecnologia de produção que sofre a externalidade da ação da justiça criminal e das condições ambientais da localidade onde o crime seria perpetrado. Cada indivíduo é diferenciado dos demais pelo custo de oportunidade da sua mão-de-obra no mercado legal e pelo prêmio esperado da ação criminosa (o preço do crime). A principal equação do modelo define que o número de crimes da localidade é determinado pelas variáveis: desigualdade de renda; renda esperada no mercado de trabalho legal (que depende da taxa de ocupação); densidade demográfica; poder de polícia; e valor da punição. Os autores implementaram empiricamente esse modelo para analisar duas décadas (anos 70 e 80) de homicídios nos Estados do Rio de Janeiro e de São Paulo. As estimati- 
vas obtidas, por meio da técnica de VAR-VEC, estatisticamente significativas, corroboram com o modelo teórico e sugerem, principalmente, duas conclusões: não há como equacionar o grave problema da segurança pública deixando de enfrentar a questão da exclusão econômica e social; e a mera alocação de recursos nos setores de segurança pública a fim de replicar o atual modelo de polícia - sem que se discuta a eficácia e eficiência - está fadada a obter desprezíveis resultados para a paz social.

\section{UM MODELO ECOLÓGICO}

Vários autores procuraram elaborar um modelo integrado para explicar a violência, cujo enfoque se dá nos vários níveis estrutural, institucional, interpessoal e individual. Tais anseios decorreram da percepção empírica de que a violência e a sua tolerância variam significativamente entre as sociedades, entre as comunidades e entre os vários indivíduos. Um primeiro uso foi de Bronfrenbrenner (1977), que procurou explicar o desenvolvimento humano e a psicologia social. Outros autores buscaram entender, por meio dessa abordagem, a etiologia de dinâmicas criminais específicas, como Belsky (1980), que se preocupou com o abuso infantil; Dutton (1988) e Edelson e Tolman (1992), que estudaram a violência doméstica contra a mulher; e Brown (1995), cujo estudo foi voltado para a coersão sexual.

Segundo essa abordagem, mais do que atribuir importância a determinadas características isoladas, o modelo - que ficou conhecido como modelo ecológico (ver Shrader, 2000) - considera que a combinação de tais atributos pertencentes àqueles diferentes níveis ocuparia um papel central na explicação da violência. Dentre as variáveis que constituiriam os níveis supramencionados, no plano individual há o histórico pessoal, os fatores ontogenéticos e as respostas da personalidade individual diante de situações de tensão. No contexto mais íntimo do indivíduo, em que a violência poderia processar-se, há as relações interpessoais com familiares e com outros conhecidos íntimos. No plano institucional figuram as associações formais e informais comunitárias, profissionais, religiosas, ou outras redes sociais em que haja a identidade dos grupos. No nível macroestrutural inserem-se as estruturas econômica, política e social que incorporam crenças e normas culturais que permeiam a sociedade, conforme apontado na Figura 1, baseada em Moser e Shrader (1999). 
Figura 1

Um Arcabouço Integrado para a Causalidade da Violência

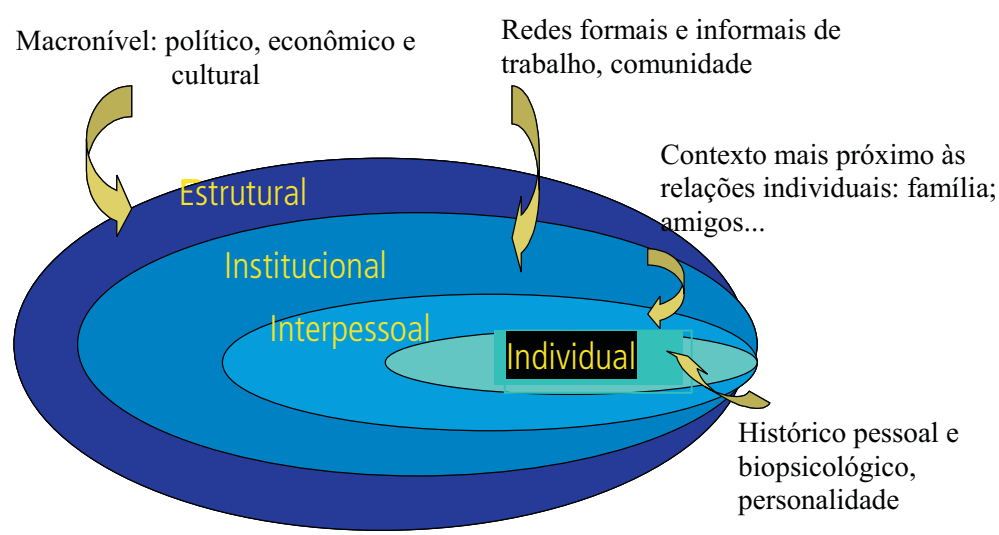

\section{CONCLUSÕES}

Neste trabalho, procurou-se investigar, com base na literatura, as várias teorias que explicariam o comportamento desviante e criminoso. Fez-se um apanhado de algumas das mais substantivas contribuições, cujas orientações metodológicas englobaram aquelas das ciências sociais e da antropologia, passando pela economia e psicologia, entre outras. Descreveu-se sucintamente o núcleo e a lógica por trás de dez conjuntos distintos de teorias que, por certo, não esgotam o universo das teorias de causação do crime, ainda que possibilitem uma compreensão bastante acurada do pensamento de estudiosos sobre o tema, desde o século passado.

Após a apresentação desses vários arcabouços - sintetizados no Quadro 2 -, ficam evidentes a complexidade do fenômeno e a dificuldade em creditar a umas poucas variáveis os determinantes da criminalidade, que tem raízes no processo distorcido de aculturação da criança desde a fase esfincteriana ( 2 ou 3 anos) até a pré-adolescência (12-13 anos), passando pela supervisão e elos com a família, com os amigos e com a escola, e terminando com outras virtuais fontes de tensão social inerentes a um espectro mais amplo que envolve as instituições e a forma de organização macroestrutural. Por outro lado, desse ambiente micro e macroestrutural decorrem os resultados acerca da distribuição do produto da economia, aferido objetivamente a partir de variáveis, como renda per capita, graus de desigualdade da renda, pro- 
babilidade de se estar empregado e acesso às oportunidades e serviços que possibilitem a obtenção de moradia, saúde (e alimentação) e cultura pelos indivíduos, condições necessárias para a inclusão social.

\section{Quadro 2}

Resumo das Várias Abordagens Teóricas sobre as Causas da Criminalidade

\begin{tabular}{|c|c|c|}
\hline Teoria & Abordagem & Variáveis \\
\hline $\begin{array}{l}\text { Desorganização } \\
\text { social }\end{array}$ & $\begin{array}{l}\text { Abordagem sistêmica em torno } \\
\text { das comunidades, entendidas } \\
\text { como um complexo sistema de } \\
\text { rede de associações formais e in- } \\
\text { formais. }\end{array}$ & $\begin{array}{l}\text { Status socioeconômico; hetero- } \\
\text { geneidade étnica; mobilidade } \\
\text { residencial; desagregação fami- } \\
\text { liar; urbanização; redes de ami- } \\
\text { zades locais; grupos de adoles- } \\
\text { centes sem supervisão; partici- } \\
\text { pação institucional; desempre- } \\
\text { go; e existência de mais de um } \\
\text { morador por cômodo. }\end{array}$ \\
\hline $\begin{array}{l}\text { Aprendizado } \\
\text { social } \\
\text { (associação } \\
\text { diferencial) }\end{array}$ & $\begin{array}{l}\text { Os indivíduos determinam seus } \\
\text { comportamentos a partir de } \\
\text { suas experiências pessoais com } \\
\text { relação a situações de conflito, } \\
\text { por meio de interações pessoais } \\
\text { e com base no processo de comu- } \\
\text { nicação. }\end{array}$ & $\begin{array}{l}\text { Grau de supervisão familiar; in- } \\
\text { tensidade de coesão nos grupos } \\
\text { de amizades; existência de ami- } \\
\text { gos com problemas com a polí- } \\
\text { cia; percepção dos jovens sobre } \\
\text { outros envolvidos em proble- } \\
\text { mas de delinqüência; jovens } \\
\text { morando com os pais; e contato } \\
\text { com técnicas criminosas. }\end{array}$ \\
\hline Escolha racional & $\begin{array}{l}\text { O indivíduo decide sua partici- } \\
\text { pação em atividades criminosas } \\
\text { a partir da avaliação racional en- } \\
\text { tre ganhos e perdas esperadas } \\
\text { advindos das atividades ilícitas } \\
\text { vis-à-vis o ganho alternativo no } \\
\text { mercado legal. }\end{array}$ & $\begin{array}{l}\text { Salários; renda familiar per capi- } \\
\text { ta; desigualdade da renda; aces- } \\
\text { so a programas de bem-estar so- } \\
\text { cial; eficiência da polícia; aden- } \\
\text { samento populacional; magni- } \\
\text { tude das punições; inércia crimi- } \\
\text { nal; aprendizado social; e edu- } \\
\text { cação. }\end{array}$ \\
\hline Controle social & $\begin{array}{l}\text { O que leva o indivíduo a não en- } \\
\text { veredar pelo caminho da crimi- } \\
\text { nalidade? A crença e a percep- } \\
\text { ção do mesmo em concordância } \\
\text { com o contrato social (acordos e } \\
\text { valores vigentes), ou o elo com a } \\
\text { sociedade. }\end{array}$ & $\begin{array}{l}\text { Envolvimento do cidadão no } \\
\text { sistema social; concordância } \\
\text { com os valores e normas vigen- } \\
\text { tes; ligação filial; amigos delin- } \\
\text { qüentes; e crenças desviantes. }\end{array}$ \\
\hline
\end{tabular}


(continuação)

\begin{tabular}{|c|c|c|}
\hline Teoria & Abordagem & Variáveis \\
\hline Autocontrole & $\begin{array}{l}\text { O não-desenvolvimento de me- } \\
\text { canismos psicológicos de auto- } \\
\text { controle na fase que segue dos } 2 \\
\text { anos à pré-adolescência, que ge- } \\
\text { ram distorções no processo de } \\
\text { socialização, pela falta de impo- } \\
\text { sição de limites. }\end{array}$ & $\begin{array}{l}\text { Freqüentemente eu ajo ao sabor } \\
\text { do momento sem medir conse- } \\
\text { qüências; e raramente deixo } \\
\text { passar uma oportunidade de go- } \\
\text { zar um bom momento. }\end{array}$ \\
\hline Anomia & $\begin{array}{l}\text { Impossibilidade de o indivíduo } \\
\text { atingir metas desejadas por ele. } \\
\text { Três enfoques: } a \text { ) diferenças de } \\
\text { aspirações individuais e os } \\
\text { meios disponíveis; } b \text { ) oportuni- } \\
\text { dades bloqueadas; e } c \text { ) privação } \\
\text { relativa. }\end{array}$ & $\begin{array}{l}\text { Participa de redes de conexões? } \\
\text { Existem focos de tensão social? } \\
\text { Eventos de vida negativos; so- } \\
\text { frimento cotidiano; relaciona- } \\
\text { mento negativo com adultos; } \\
\text { brigas familiares; desavenças } \\
\text { com vizinhos; e tensão no traba- } \\
\text { lho. }\end{array}$ \\
\hline Interacional & $\begin{array}{l}\text { Processo interacional dinâmico } \\
\text { com dois ingredientes: } a \text { ) pers- } \\
\text { pectiva evolucionária, cuja car- } \\
\text { reira criminal se inicia aos } 12-13 \\
\text { anos, ganha intensidade aos } \\
16-17 \text { e finaliza aos } 30 \text { anos; e } b \text { ) } \\
\text { perspectiva interacional que en- } \\
\text { tende a delinqüência como cau- } \\
\text { sa e conseqüência de um conjun- } \\
\text { to de fatores e processos sociais. }\end{array}$ & $\begin{array}{l}\text { As mesmas daquelas constantes } \\
\text { nas teorias do aprendizado so- } \\
\text { cial e do controle social. }\end{array}$ \\
\hline Ecológico & $\begin{array}{l}\text { Combinação de atributos per- } \\
\text { tencentes a diferentes categorias } \\
\text { condicionaria a delinqüência. } \\
\text { Esses atributos, por sua vez, es- } \\
\text { tariam incluídos em vários ní- } \\
\text { veis: estrutural, institucional, } \\
\text { interpessoal e individual. }\end{array}$ & $\begin{array}{l}\text { Todas as variáveis anteriores } \\
\text { podem ser } \\
\text { utilizadas nessa abordagem. }\end{array}$ \\
\hline
\end{tabular}

Em uma outra mão, existem as variáveis dissuasórias que levariam o indivíduo a se abster de cometer crimes. Dentre essas há, em primeiro lugar, o controle interno individual (controle social), traduzido aqui pela percepção e sentimento de concordância do indivíduo para com o conjunto vigente de normas e valores sociais, que faz estreitar os elos desse para com a sociedade. Por fim, há o controle externo, imposto pelas instituições pertencentes ao fluxo de justiça criminal, que se inicia pela polícia, passando pela justiça e terminando nos sistemas 
punitivos, que indicariam as probabilidades de aprisionamento e a magnitude das punições.

A depender da cultura, da região e do momento histórico vivido, algumas dessas variáveis podem incidir de forma mais decisiva para explicar determinada dinâmica criminal. Muitas vezes elas interagem em vários níveis, conforme apontado no modelo ecológico, fazendo com que as próprias dinâmicas criminais funcionem como motivadoras de outras.

Fica evidente, portanto, a partir da exposição dos vários modelos que explicam os determinantes da criminalidade, tratar-se de um fenômeno complexo e multifacetado, mas que possui determinadas regularidades estatísticas que variam conforme a região e a dinâmica criminal, em particular. As pesquisas empíricas desenvolvidas nas últimas décadas, por outro lado, dão conta da enorme dificuldade em se conseguir resultados satisfatórios que levem a corroborar as inúmeras hipóteses e modelos. Tal dificuldade é fruto, de um lado, da precariedade (indisponibilidade e não-confiabilidade) dos poucos dados existentes que permitiriam a execução dos exercícios, e de outro, dos enormes desafios metodológicos inerentes à resolução do problema e à aferição das hipóteses, que leva, quase sempre, o pesquisador a utilizar caminhos indiretos, que pressupõem uma série de hipóteses, às vezes, por demais simplificadoras.

(Recebido para publicação em agosto de 2003)

(Versão definitiva em maio de 2004)

\section{NOTAS}

1. Popper (1978) afirma que as teorias físicas são verdades temporárias. Conforme aponta Silveira (1994), o comprometimento maior dos "cientistas naturais" se dá na formalização hipotético-dedutiva e na linguagem lógica e formal. Nas ciências sociais, por outro lado, teorias minimamente realistas não poderiam deixar de ignorar instituições e uma série de outros elementos muitas vezes não quantificáveis ou tratáveis matemática ou logicamente. Desse modo, em vista da miríade de fatores relevantes e da enorme complexidade sempre imanente aos fenômenos sociais, ainda que uma teoria social obtivesse um consenso, em determinado momento, na 


\section{Determinantes da Criminalidade: Arcabouços Teóricos e Resultados Empíricos}

academia, essa teoria deveria constituir-se apenas em uma meia verdade temporária.

2. Uma descrição melhor dos métodos e resultados obtidos por esses autores pode ser vista em Entorf e Spengler (2002).

3. Quer dizer, a variável explicativa sendo também explicada simultaneamente pela variável dependente.

4. É o Programa de Ajuda para Famílias com Crianças Dependentes (Aid to Families with Dependent Children - AFDC). Esse é um dos maiores programas compensatórios americanos para a população de baixa renda, junto ao Medicaid e ao Public Housing Assistance.

5. Verificar que, apesar de o elemento motivador ser o mesmo, as explicações diferem substancialmente da ótica sociológica para a econômica.

6. Alguns exemplos citados foram os estudos relacionados aos Estados Unidos em que Cantor e Land (1985) concluíram por uma relação positiva e estatisticamente significativa entre desemprego e crime, ao passo que Land, Cantor e Russell (1994) chegam a uma relação inversa. Por outro lado, há estudos para a Inglaterra que mostram uma relação contemporânea positiva entre essas duas variáveis, ao passo que a relação é nula, quando o emprego é defasado um período.

7. Para maiores detalhes sobre capital social, ver Lederman et alii (1999).

\section{REFERÊNCIAS BIBLIOGRÁFICAS}

AGNEW, R. (1984), "Goal Achievement and Delinquency". Sociology and Social Research, vol. 68, pp. 435-451.

. (1987), "Testing Structural Strain Theories". Journal of Research in Crime and Delinquency, vol. 24, pp. 281-286.

. (1991), "A Longitudinal Test of Social Control Theory and Delinquency". Journal of Research in Crime and Delinquency, vol. 28, pp. 126-156.

(1992), "Foundation for a General Strain Theory of Crime and Delinquency". Criminology, vol. 30, pp. 47-87.

. (1993), "Why do They do It? An Examination of the Intervening Mechanisms between Social Control Variables and Delinquency". Journal of Research in Crime and Delinquency, vol. 30, pp. 245-266.

e WHITE, H. R. (1992), “An Empirical Test of General Strain Theory”. Criminology, vol. 30, pp. 475-499.

ANDRADE, M. V. E. e LISBOA, M. B. (2000), “Desesperança de Vida: Homicídio em Minas Gerais, Rio de Janeiro e São Paulo - 1981 a 1997" , in R. Henriques (org.), Desigualdade e Pobreza no Brasil. Rio de Janeiro, IPEA. 


\section{Daniel Cerqueira e Waldir Lobão}

ARNEKLEV, B. J., GRASMICK, H. G., TITTLE, C. R. e BURSIK, R. J. (1993), “Low Self-control and Imprudent Behavior". Journal of Quantitative Criminology, vol. 9, pp. 225-247.

BEATO, C. C. e REIS, I. A. (2000), “Desigualdade, Desenvolvimento Socioeconômico e Crime", in R. Henriques (org.), Desigualdade e Pobreza no Brasil. Rio de Janeiro, IPEA.

BECKER, G. (1968), “Crime and Punishment: An Economic Approach”. Journal of Political Economy, vol. 76, pp. 169-217.

BELSKY, J. (1980), “Child Maltreatment an Ecological Integration”. American Psychologist, vol. 35, no 4 , p. 320-335.

BLAU, J. R. e BLAU, P. M. (1982), “The Cost of Inequality: Metropolitan Structure and Violent Crime". American Sociological Review, vol. 47, no 1 .

BLOCK, M. K. e HEINECKE, J. M. (1975), “A Labor Theoretic Analysis of the Criminal Choice". American Economic Review, vol. 65, pp. 314-325.

BRONFRENBRENNER, U. (1977), “Toward an Experimental Ecology of Human Development". American Psychologist, vol. 32, pp. 513-531.

BROWN, S. (1995), "Gender Stereotypes and Sexual Coercion", in L. Heise, K. Moore e N. Toubia (eds.), Sexual Coercion and Reproductive Health. New York, The Population Council, pp. 28-30.

BRUINSMA, G. J. (1992), “Differential Association Theory Reconsidered: An Extension and Its Empirical Test". Journal of Quantitative Criminology, vol. 8, pp. 29-49.

BURSIK, R. (1986), “Delinquency Rates as Source of Ecological Change”, in J. Byrne e R. Sampson (eds.), The Social Ecology. New York, Berlin/Heidelberg, pp. 63-72.

BURTON JR., V. S. e CULLEN, F. T. (1992), “The Empirical Status of Strain Theory”. Crime and Justice, vol. 15, pp. 1-30.

, EVANS, T. D. e DUNAWAY, R. G. (1994), “Reconsidering Strain Theory: Operationalization, Rival Theories and Adult Criminality". Journal of Quantitative Criminology, vol. 10, pp. 213-239.

CANO, I. e SANTOS, N. (2001), Violência Letal, Renda e Desigualdade no Brasil. Rio de Janeiro, 7 Letras.

CANO, I. e SOARES, G. D. (2002), As Teorias sobre as Causas da Criminalidade. Rio de Janeiro, IPEA. Manuscrito.

CANTOR, D. e LAND, K. C. (1985), "Unemployment and Crime Rates in the Post-World War II United States: A Theoretical and Empirical Analysis". American Sociological Review, vol. 50, pp. 317-332.

CERQUEIRA, D. R. C. e LOBÃO, W. A. J. L. (2003), “Condicionantes Sociais, Poder de Polícia e o Setor de Produção Criminal". Texto para Discussão, no 957, IPEA.

COELHO, E. C. (1988), “A Criminalidade Urbana Violenta”. Dados, vol. 31, no 2, pp. 145-183.

COHEN, A. K. (1955), Delinquent Boys. New York, Free Press. 


\section{Determinantes da Criminalidade: Arcabouços Teóricos e Resultados Empíricos}

CRESSEY, D. P. (1968), "Crime: Causes of Crime in International Encyclopedia of the Social Sciences". The Macmillan Company/The Free Press Ed.

DALY, M. e WILSON, M. (1983), Sex, Evolution, and Behavior (2 ${ }^{\mathrm{a}}$ ed.). Boston, PWS Publishers.

(1988), Homicide. New York, A. de Gruyter.

(1999), The Truth about Cinderella: A Darwinian View of Parental Love. New Haven, Conn., Yale University Press.

DUTTON, D. G. (1988), “Profiling of Wife Assaulters: Preliminary Evidence for a Trimodal Analysis". Violence and Victims, vol. 3, pp. 5-29.

EDELSON, J. e TOLMAN, R. M. (1992), Intervention for Men Who Batter: An Ecological Approach. Knobbier Park, CA, Sage Publications.

EHRLICH, I. (1973), “Participation in Illegitimate Activities: A Theoretical and Empirical Investigation". Journal of Political Economy, vol. 81, pp. 521-565.

. (1996), "Crime, Punishment, and the Market for Offenses". Journal of Economic Perspectives, vol. 10, pp. 43-67.

ELLIOT, D. S. e VOSS, H. (1974), Delinquency and Dropout. Lexington, MA, Lexington Books.

ENTORF, H. e SPENGLER, H. (2000), "Socioeconomic and Demographic Factors of Crime in Germany: Evidence from Panel Data of the German States". International Review of Law and Economics, vol. 20, pp. 75-106.

_. (2002), Crime in Europe Causes and Consequences. Berlin, Ed. Springer.

FAJNZYLBER, P., LEDERMAN, D. e LOAYZA, N. (1998), Determinants of Crime Rates in Latin America and the World: An Empirical Assessment. Washington, DC, World Bank Latin American and Caribbean Studies.

FREEMAN, R. B. (1994), “Crime and the Job Market”. Working Paper, nํ⒋910, Cambridge, MA, NBER.

GIBBS, J. J., GIEVER, D. e MARTIN, J. S. (1998), "Parental Management and Self-control: An Empirical Test of Gottfredson and Hirschi's General Theory". Journal of Research in Crime and Delinquency, vol. 35, pp. 40-70.

GLAESER, E. L. e SCHEINKMAN, J. A. (1996), “Crime and Social Interactions". Quarterly Journal of Economics, vol. 111, pp. 507-548.

GLUECK, B. (1918), “Concerning Prisioners”. Mental Hygiene, vol. 2, pp. 85-151.

GOTTFREDSON, D. C. e HIRSCHI, T. (1990), A General Theory of Crime. Stanford, CA, Stanford University Press.

GOULD, E. D., WEINBERG, B. A. e MUSTARD, D. B. (2000), “Crime Rates and Local Labor Market Opportunities in the United States: 1979-1997". JEL Codes, K 4, J 0, pp. $1-58$.

GREENBERG, D. F. (1977), “Delinquency and the Age Structure of Society". Contemporary Crises, vol. 1, pp. 189-223. 


\section{Daniel Cerqueira e Waldir Lobão}

HAKEEM, M. (1958), "A Critique of Psychiatric Approach to Crime and Correction". Law and Contemporary Problems, vol. 23, pp. 650-682.

HEALY, W. (1915), The Individual Delinquent: A Text-book of Diagnosis and Prognosis for all Concerned in Understanding Offenders. Boston, Little Brown.

HOFFMANN, J. P. e MILLER, A. S. (1998), “A Latent Variable Analysis of General Strain Theory". Journal of Quantitative Criminology, vol. 14, pp. 83-110.

HORNEY, J., OSGOOD, D. W. e MARSHALL, I. H. (1995), "Criminal Careers in the Short-term: Intra-individual Variability in Crime and its Relation to Local Life Circumstances". American Sociological Review, vol. 60, pp. 655-673.

JUNGER-TAS, J. (1992), “An Empirical Test of Social Control Theory". Journal of Quantitative Criminology, vol. 8, pp. 9-28.

KATZMAN, M. T. (1980), "The Contribution of Crime to Urban Decline". Urban Studies, vol. 17, pp. 277-286.

LAND, K. C., CANTOR, D. e RUSSELL, T. (1994), “Unemployment and Crime Rate Fluctuations in the Post-World War II United States: Statistical Time Series Properties and Alternative Models", in J. Hagan e R. D. Peterson (eds.), Crime and Inequality. Stanford, CA, Stanford University Press.

LEDERMAN, D., LOAYZA, N. e MENÉNDEZ, A. M. (1999), Violent Crime: Does Social Capital Matter? Washington, DC, The World Bank.

LEUNG, S. F. (1995), “Dynamic Deterrence Theory”. Economica, no 62, pp. 65-87.

LOMBROSO, C. (1968) [1911], Crime, its Causes and Remedies (Traduzido para o inglês por H. P. Horton, N. J. Montclair e S. Patterson).

MATSUEDA, R. L. (1982), “Testing Control Theory and Differential Association: A Casual Modeling Approach". American Sociological Review, vol. 47, pp. 489-504.

MCCARTHY, B. (1996), “The Attitudes and Actions of Others: Tutelage and Sutherland's Theory of Differential Association". British Journal of Criminology, vol. 36, pp. 135-147.

MENDONÇA, M. J. (2000), Um Modelo de Criminalidade para o Caso Brasileiro. IPEA. Manuscrito.

MERTON, R. K. (1938), "Social Structure and Anomie". American Sociological Review, vol. 3, pp. 672-682.

MESSNER, S. F. e BLAU, J. R. (1987), “Routine Leisure Activities and Rates of Crime: A Macro-level Analysis". Social Forces, vol. 65, pp. 1.035-1.052.

MIETHE, T. D., HUGHES, M. e MCDOWALL, D. (1991), "Social Change and Crime Rates: An Evaluation of Alternative Theoretical Approaches". Social Forces, vol. 70, pp. 165-185.

MIETHE, T. D., STAFFORD, M. C. e LONG, J. S. (1987), “Social Differentiation in Criminal Victimization: A Test of Routine Activities/Lifestyle Theories". American Sociological Review, vol. 52, pp. 184-194.

MOSER, C. e SHRADER, E. (1999), A Conceptual Framework for Violence Reduction. Washington, D. C., World Bank, Latin American and Caribbean Region, Environ- 


\section{Determinantes da Criminalidade: Arcabouços Teóricos e Resultados Empíricos}

mentally and Socially Sustainable Development SMU (LCR Sustainable Development Working Paper no $²$ ).

OSGOOD, D. W., WILSON, J. K., O'MALLEY, P. M., BACHMAN, J. G. e JOHNSTON, L. D. (1996), "Routine Activities and Individual Deviant Behavior". American Sociological Review, vol. 61, pp. 625-655.

PAIXÃO, A. L. (1988), “Crime, Controle Social e Consolidação da Democracia”, in F. W. Reis e G. O’Donnell (orgs.), A Democracia no Brasil: Dilemas e Perspectivas. São Paulo, Vértice.

PALLONE, N. J. e HENNESSY, J. J. (2000), “Neuropathology and Criminal Violence: Newly Calibrated Ratios". Journal of Offender Rehabilitation, vol. 31, nos. 1 e 2, pp. 87-99.

PATERNOSTER, R. e MAZEROLLE, P. (1994), “General Strain Theory and Delinquency: A Replication and Extension". Journal of Research in Crime and Delinquency, vol. 31, pp. 235-263.

PEZZIN, L. (1986), Criminalidade Urbana e Crise Econômica. São Paulo, IPE/USP.

POLAKOWSKI, M. (1994), “Linking Self and Social Control with Deviance: Illuminating the Structure Underlying a General Theory of Crime and its Relation to Deviant Activity". Journal of Quantitative Criminology, vol. 10, pp. 41-78.

POPPER, K. R. (1978), Lógica das Ciências Sociais. Rio de Janeiro, Tempo Brasileiro/Universidade de Brasília.

POSADA, C. (1994), “Modelos Económicos de la Criminalidad y la Posibilidad de una Dinámica Prolongada". Planeación y Desarrollo, no 25.

REISS JR., A. J. e RHODES, A. L. (1963), “Status Deprivation and Delinquent Behavior". Sociological Quarterly, vol. 4, pp. 135-149.

RONCEK, D. W. e MAIER, P. A. (1991), “Bars, Blocks, and Crime Revisited: Linking the Theory of Routine Activities to the Empiricism of Hot Spots". Criminology, vol. 29, pp. 725-753.

SAH, R. (1991), "Social Osmosis and Patterns of Crime". Journal of Political Economy, no 99.

SAMPSON, R. J. (1995), “The Community", in J. Q. Wilson e J. Petersilia (eds.), Crime. San Francisco, ICS Press, pp. 193-216.

. (1997), “Collective Regulation of Adolescent Misbehaviour: Validation Results from Eighty Chicago Neighborhoods". Journal of Adolescent Research, vol. 12, pp. 227-244.

e GROVES, W. B. (1989), "Community Structure and Crime: Testing Social-Disorganization Theory". American Journal of Sociology, vol. 94, pp. 774-802.

SAMPSON, R. J. e WOOLDREDGE, J. D. (1986), "Evidence that High Crime Rates Encourage Migration Away from Central Cities". Sociology and Social Research, vol. 70, pp. 310-314. 


\section{Daniel Cerqueira e Waldir Lobão}

SAPORI, L. F. e WANDERLEY, C. B. (2001), A Relação entre Desemprego e Violência na Sociedade Brasileira: Entre o Mito e a Realidade. Fundação João Pinheiro, Belo Horizonte, pp. 1-24. Manuscrito.

SHRADER, E. (2000), Methodologies to Measure the Gender Dimensions of Crime and Violence. Washington, DC, World Bank.

SILVEIRA, A. M. (1994), "Teorias Econômicas: A Meia-verdade Temporária”. Revista Brasileira de Economia, vol. 48, pp. 203-216.

SKOGAN, W. (1986), "Fear of Crime and Neighborhood Change", in A. J. Reiss Jr. e M. Torny (eds.), Communities and Crime. Chicago, IL, University of Chicago Press, pp. 203-229.

(1991), Disorder and Decline. New York, Free Press.

SMITH, D. A. e JARJOURA, G. R. (1988), "Social Structure and Criminal Victimization". Journal of Research in Crime and Delinquency, vol. 25, pp. 27-52.

SOARES, G. A. D. (1968), “Marxism as a General Sociological Orientation”. British Journal of Sociology, vol. XIX, pp. 365-374.

SUTHERLAND, E. H. (1973) [1942], "Development of the Theory", in K. Schuessler (ed.), Edwin Sutherland on Analyzing Crime. Chicago, IL, Chicago University Press, pp. 30-41.

TAUCHEN, H., WITTE, A. D. e GRIESINGER, H. (1994), “Criminal Deterrence: Revisiting the Issue with a Birth Cohort". Review of Economics and Statistics, vol. 76, pp. 399-412.

THORNBERRY, T. P. (1996), "Empirical Support for Interactional Theory: A Review of the Literature", in J. D. Hawkins (ed.), Some Current Theories of Crime and Deviance. New York, Cambridge University Press, pp. 198-235.

TOLMAN, F. L. (1902/1903), “The Study of Sociology in Institutions of Learning in the United States". American Journal of Sociology, vol. 7, pp. 797-838.

TREMBLAY, M. e TREMBLAY, P. (1998), "Social Structure, Interaction Opportunities and the Direction of Violent Offenses". Journal of Research in Crime and Delinquency, vol. 35, pp. 295-315.

TRUMBULL, W. N. (1989), “Estimations of the Economic Model of Crime Using Aggregate and Individual Level Data". Southern Economic Journal, vol. 56, pp. 423-439.

WARNER, B. D. e PIERCE, L. (1993), “Reexamining Social Disorganization Theory Using Calls to the Police as a Measure of Crime". Criminology, vol. 31, pp. 493-517.

WITTE, A. D. (1980), "Estimating the Economic Model of Crime with Individual Data". Quarterly Journal of Economics, vol. 94, pp. 57-84.

WOLPIN, K. (1978), "An Economic Analysis of Crime and Punishment in England and Wales, 1894-1967". Journal of Political Economy, vol. 86, pp. 815-840.

ZALUAR, A. (1985), A Máquina e a Revolta. As Organizações Populares e o Significado da Pobreza. São Paulo, Editora Brasiliense.

ZHANG, J. (1997), “The Effects of Welfare Programs on Criminal Behavior: A Theoretical and Empirical Analysis". Economic Inquiry, vol. 35, pp. 120-137. 


\begin{tabular}{|l|l|c|}
\hline \multicolumn{2}{|c|}{ ANEXO } \\
\hline Nível & \multicolumn{1}{|c|}{ Variáveis Explicativas } & \multicolumn{1}{|c|}{ Ator } \\
\hline Individual & $\begin{array}{l}\text { Concordância com os valores e } \\
\text { normas vigentes; e crenças } \\
\text { desviantes. }\end{array}$ & \multicolumn{1}{|c|}{ Indivíduo } \\
\hline Interpessoal & $\begin{array}{l}\text { Desagregação familiar; grau de } \\
\text { supervisão familiar; jovens } \\
\text { morando com os pais; e ligação } \\
\text { filial. }\end{array}$ \\
\hline & $\begin{array}{l}\text { Redes de amizades locais; } \\
\text { intensidade de coesão nos } \\
\text { grupos de amizades; percepção } \\
\text { dos jovens sobre outros } \\
\text { envolvidos em problemas de } \\
\text { delinqüência; contato com } \\
\text { técnicas criminosas; amigos } \\
\text { delinqüentes; desavenças com } \\
\text { vizinhos; e participa de redes } \\
\text { de conexões? Existem focos de } \\
\text { tensão social? Eventos de vida } \\
\text { negativos; sofrimento } \\
\text { cotidiano; e relacionamento } \\
\text { negativo com adultos. }\end{array}$ & Amigos \\
\hline Institucional & $\begin{array}{l}\text { Grupos de adolescentes sem } \\
\text { supervisão; e ligação e } \\
\text { compromisso com a escola. }\end{array}$ & Escola \\
\hline $\begin{array}{l}\text { Heterogeneidade étnica; } \\
\text { mobilidade residencial; } \\
\text { urbanização; grupos de } \\
\text { adolescentes sem supervisão; } \\
\text { participação institucional; } \\
\text { status socioeconômico; e } \\
\text { aprendizado social. }\end{array}$ & $\begin{array}{l}\text { Associações culturais, despor- } \\
\text { tivas, religiosas }\end{array}$ \\
\hline Tensão no trabalho. & $\begin{array}{l}\text { Participação institucional. } \\
\text { Combional }\end{array}$ \\
\hline
\end{tabular}

(continua) 
Daniel Cerqueira e Waldir Lobão

(continuação)

\begin{tabular}{|l|l|c|}
\hline Nível & \multicolumn{1}{|c|}{ Variáveis Explicativas } & \multicolumn{1}{c|}{ Ator } \\
\hline $\begin{array}{l}\text { Estrutural } \\
\text { Social }\end{array}$ & $\begin{array}{l}\text { Status socioeconômico; } \\
\text { desemprego; existência de } \\
\text { mais de um morador por } \\
\text { cômodo; adensamento } \\
\text { populacional; inércia criminal; } \\
\text { educação; salários; renda } \\
\text { familiar per capita; } \\
\text { desigualdade da renda; e } \\
\text { acesso a programas de } \\
\text { bem-estar social. }\end{array}$ & Estado \\
\hline $\begin{array}{l}\text { Fluxo de justiça } \\
\text { criminal }\end{array}$ & \begin{tabular}{l} 
Eficiência da polícia. \\
\hline
\end{tabular} & $\begin{array}{l}\text { Eficiência da justiça; e } \\
\text { magnitude das punições. }\end{array}$ \\
\hline & $\begin{array}{l}\text { Participação em programas de } \\
\text { reinserção. }\end{array}$ & $\begin{array}{l}\text { Unidades de reclusão para } \\
\text { infratores da lei }\end{array}$ \\
\hline
\end{tabular}




\section{ABSTRACT}

Determinants of Crime: Theoretical Frameworks and Empirical Results

What makes people commit crimes and socially deviant behaviors? Are such acts the result of idiosyncratic personal characteristics or a deformed acculturation process in the pre-adult phase? Or could they be the result of social breakdown and injustice? On the other hand, one could postulate that such phenomena are the result of the rationalization process, whereby the modern culture of individualization provides the ethical underpinnings for opposing the Golden Rule. How, then, does one explain the occurrence of such phenomena throughout history and in different places and cultures? This paper provides a summary of different contributions and also reviews some theoretical models concerning the determinants of crime and their relationship to several empiric studies.

Key words: determinants of crime; violence

\section{RÉSUMÉ \\ Déterminants de la Criminalité: Schémas Théoriques et Résultats Empiriques}

Qu'est-ce qui mène les gens à perpétrer des crimes et à adopter des conduites déviantes? Ces conduites seraient-elles le fruit de traits personnels et d'idiosyncrasies, ou bien le résultat d'un processus déformé d'acculturation au stade pré-adulte? Ou encore seraient-elles le résultat d'une ambiance de désagrégation et d'injustices sociales ? On peut proposer, par ailleurs, l'hypothèse selon laquelle le dit phénomène n'est que l'aboutissement d'un processus de rationalisation, où la culture moderne de l'individualisation serait la base éthique qui s'opposerait à la Loi de l'Or. Dans ce cas, comment pourrait-on expliquer l'existence de ces phénomènes tout au long de l'histoire dans des lieux et cultures aussi divers? Dans cet article, on cherche à examiner quelques-unes de ces contributions et schémas théoriques ainsi que leur rapport avec des travaux empiriques quantitatifs, tout en discutant certaines de leurs limitations et la portée de leurs résultats face aux restrictions des données.

Mots-clé: déterminants de la criminalité; violence 